\title{
En torno al prólogo y las notas de la traducción al español del Codex, Pharmacopée française de 1837
}

\author{
Manuela ÁlvAREz JURAdo \\ Universidad de Córdoba \\ ff1aljum@uco.es \\ https://orcid.org/oooo-0003-3243-7672
}

\section{Resumen}

Las farmacopeas o Códex nacen de la necesidad de establecer un texto que contenga unas normas de referencia que garanticen la seguridad y eficacia de los productos farmacéuticos. Los grandes avances decimonónicos en el ámbito de la Química y de la Farmacia condujeron a una actualización de estas obras con la incorporación de nuevas elaboraciones. Entre la cuarta edición de la Pharmacopoea Hispana y la siguiente edición de 1865, transcurrieron 48 años sin que hubiera una farmacopea oficial, lo que propició que Manuel Jiménez se decidiera a traducir la Pharmacopée française de 1837. En el presente estudio analizamos las instancias paratextuales de esta traducción, concretamente el prólogo y las notas del traductor, en las que este se hace visible y ejerce como mediador entre dos culturas diferentes.

Palabras clave: historia de la traducción, siglo XIX, instancias paratextuales, visibilidad del traductor, mediación cultural.

\section{Résumé}

Les pharmacopées ou Codex naissent du besoin d'établir un texte contenant des normes de référence garantissant la sécurité et l'efficacité des produits pharmaceutiques. Au XIX ${ }^{\mathrm{e}}$ siècle, les grands progrès réalisés dans le domaine de la Chimie et de la Pharmacie ont conduit à une actualisation de ces œuvres avec de nouvelles élaborations. Entre la quatrième édition de la Pharmacopoea Hispana et l'édition suivante de 1865, 48 années se sont écoulées sans pharmacopée officielle : ceci favorisa que Manuel Jiménez décida de traduire la Pharmacopée française de 1837. Dans cette étude, nous analysons les instances paratextuelles de ladite traduction, tout particulièrement la préface et les notes du traducteur qui se rend ainsi visible et qui fait office de médiateur entre deux cultures différentes.

Mots clé : histoire de la traduction, $\mathrm{XIX}^{\mathrm{e}}$ siècle, instances paratextuelles, visibilité du traducteur, médiation intertextuelle.

\section{Abstract}

\footnotetext{
*Artículo recibido el 6/04/2021, aceptado el 22/05/2021.
} 
Pharmacopeias or Codex arise from the necessity of establishing a text which contains some reference rules which may guarantee the safety and the usefulness of pharmaceutical products. The significant advancements which took place in the fields of Chemistry and Pharmacy during the nineteenth-century led to an update of these works, in order to include the preparations which had recently been formulated. Forty-eight years passed between the fourth edition of the Pharmacopoea Hispana and the next one, published in 1865. Thus, during all this period there was an absence of an official pharmacopeia. Consequently, Manuel Jiménez decided to translate the 1837 Pharmacopée française. This paper analyzes the paratextual instances of this translation, specifically the prologue and the translator's notes, where the translator becomes visible and acts as a mediator between two different cultures.

Keywords: history of translation, nineteenth century, paratextual instances, translator's visibility, cultural mediation.

\section{Introducción}

La presencia del traductor en la obra traducida ha hecho correr ríos de tinta, ya que son numerosos los escritores que han reflexionado al respecto y muy diversas, e incluso opuestas, las opiniones vertidas, que se pueden resumir en la frase emitida por Berman (2001: 17): «Parler de traduction, [...] c'est parler du mensonge et de la vérité, de la trahison et de la fidélité». Para unos, en el texto meta no debe aparecer ninguna huella del traductor, mientras que otros, sin embargo, consideran que, de una manera $\mathrm{u}$ otra, este debe estar presente para que el lector no se sienta en modo alguno engañado ni traicionado y sea consciente de que se encuentra ante una traducción y no ante un texto original. No entraremos en consideraciones sobre la fidelidad o traición al texto origen, ya que este concepto difiere mucho en el contexto del siglo XIX en el que se publica y se traduce la obra que vamos a analizar. Nuestro interés se centra en la indiscutible presencia del traductor decimonónico de obras de carácter científico-técnico, probablemente con la intención (precisamente) de exponer los motivos que le llevan a traducir esa obra y no otra. Al tratarse de obras cuya finalidad es meramente pragmática, el traductor se ve en la necesidad de despejar cualquier duda que la traducción pudiera despertar en el lector, lo que le lleva a intervenir a través de las instancias paratextuales. En efecto, el prólogo y las notas se convierten en el espacio idóneo para que el traductor se haga visible.

Es evidente que para teorizar sobre la figura del traductor y sobre la relación que este establece con el autor, con el texto, con el editor y con el lector, es necesaria su presencia en el texto, ya que su invisibilidad dificulta sobremanera su estudio. Guzmán y Guzmán (2009: 206) se preguntan: «¿Cómo se teoriza a un sujeto ausente? ¿Cómo hablar del traductor y ubicarlo en el centro de la investigación crítica?». La posibilidad de estudio de la presencia del traductor en el texto traducido nos la brindan, sin duda, las 
traducciones de los siglos XVIII y XIX, en las que el traductor como mediador ejerce un papel de gran calado dejando atrás la tradicional imagen del traductor como escriba, copista o mensajero neutro de un mensaje estable (Guzmán y Guzmán, 2009: 206). Ya en el siglo XVIII el oficio de traductor tomó gran auge en España gracias a instituciones como la Secretaría de Interpretación de Lenguas, que realizaba traducciones por encargo tanto de instituciones como de particulares. Como consecuencia de este apoyo a la traducción, un gran número de traductores con buena formación lingüística se dedicaron a traducir todo tipo de documentos. Sin embargo, otros tantos traductores (y estos son los que en esta ocasión nos interesan) se consagraron a la traducción de textos científicos y técnicos ejerciendo una encomiable labor al contribuir a la difusión del conocimiento científico en otros idiomas. La mayoría de estos traductores tenía una sólida formación científica, lo que aportó calidad a las traducciones que realizaron. Así pues, numerosos fueron los farmacéuticos que llevaron a cabo traducciones de obras científicas, como por ejemplo Bonet, quien tradujo del francés una obra de Garnier y Morel sobre la adulteración de sustancias alimenticias en 1846, obra que fue continuada por Gómez Pamo con la traducción del libro de Souberain, Nuevo diccionario de falsificaciones y alteraciones de los alimentos, publicado en 1894. Toda la información aportada por estas obras fue puesta en práctica inmediatamente por un gran número de químicos, médicos, farmacéuticos e ingenieros industriales (Álvarez Jurado, 2016: 294).

Estudiaremos la relación que el traductor decimonónico establece con el texto original, así como los mecanismos a través de los cuales se revela su presencia en la obra traducida. Con la intención de rastrear esta presencia del traductor, hemos seleccionado como corpus textual de estudio el Código de medicamentos o Farmacopea francesa, traducción al español llevada a cabo en 1840 por Manuel Jiménez Murillo a partir del Codex, Pharmacopée française de 1837. La inmediatez de la traducción de esta obra responde (según manifiesta el propio traductor en el prólogo) a la necesidad tanto de médicos y de farmacéuticos como de profesores de Medicina y de Farmacia de disponer de una farmacopea actualizada en la que se incorporaran los nuevos avances y descubrimientos, ya que, desde la última edición de la Pharmacopoea Hispana en 1817, no se había vuelto a publicar un nuevo texto revisado, habiendo ya transcurrido veintitrés años. En efecto, puede resultar sorprendente la figura de un traductor decimonónico omnipresente que, como podremos comprobar, toma en ocasiones incluso mayor relevancia que el propio autor, llegando a fagocitarlo haciendo desaparecer su huella del texto original.

Aunque en la actualidad se puede constatar un manifiesto desinterés por el prólogo del traductor entre críticos y teóricos de la traducción (Letawe, 2018), debido a que no es frecuente su aparición en la obra traducida, sin embargo, hemos podido comprobar su presencia en numerosas obras científicas decimonónicas. El propio Genette (2002: 267) tan solo dedicó 
una nota a pie de página al prólogo del traductor: «En cas de traduction, la préface peut être [...] signée du traducteur. Le traducteur-préfacier peut éventuellement commenter, entre autres, sa propre traduction ; sur ce point et en ce sens, sa préface cesse alors d'être allographe».

Partiremos precisamente del concepto de «instancias paratextuales » de Genette (1982) para dar fe de cómo en el siglo XIX el traductor se sirve de los diferentes elementos textuales para emerger en el texto y comunicar al lector la finalidad que le ha conducido a tomar la decisión de traducir una obra y no otra. Asimismo, el traductor a través del peritexto (en el caso que nos ocupa, del prólogo y sus notas) reflexiona acerca de las dificultades que ha encontrado en el proceso traductológico y sobre las opciones traductoras que ha elegido. De este modo, el prólogo del traductor decimonónico se convierte en un laboratorio de la obra traducida, un auténtico tratado teórico que revela los secretos del traductor (Risterucci-Roudnicky, 2008: 51).

Para Berman (1989: 672), «dès le début de la tradition occidentale, l'activité traduisante s'est accompagnée d'un discours sur la traduction». Así pues, nos encontramos ante un paratexto metadiscursivo que constituye el lugar privilegiado de reflexión del traductor y a través del cual este se comunica con el lector haciéndole partícipe y, en cierto modo, cómplice del nuevo texto traducido. Nos basaremos en André Lefevere (1992) para quien las traducciones son rewritings, es decir, reescrituras de un texto original en las que interviene la lengua a la que se traducen, las tradiciones de las que proceden, así como un complejo entramado de circunstancias que configuran y condicionan de algún modo el texto traducido. En efecto, considerando la traducción como reescritura marcada por unas contingencias determinadas, en el caso de la traducción decimonónica cobra aún más sentido, ya que el traductor no sólo traduce, sino que reescribe la obra original por medio de la adición de nuevos elementos, de la supresión de otros o de la introducción de comentarios a través del prólogo y de las notas situadas a pie de página o notas del traductor.

Por último, tomaremos en consideración a Yuste Frías (2010: 287) para quien «no existe traducción sin paratraducción». A través de la paratraducción se invita al traductor a leer, interpretar y paratraducir todo símbolo y toda imagen que rodea, envuelve, acompaña, prolonga y presenta al texto en los márgenes, en los umbrales de la traducción (Yuste Frías, 2011: 66). El enfoque paratraductivo de la traducción estudia cómo los paratextos pueden influir sobre la manera en que un nuevo público percibe una literatura traducida. Los lectores, antes de entrar en el texto traducido, perciben el mensaje que les transmite el traductor a través del prólogo. De este modo, los paratextos no solo acompañan al texto y lo presentan, sino que además ofrecen una nueva perspectiva que permite investigar la traducción como transmisión cultural (Tahir- Gürçağlar, 2002: 52).

Nuestro estudio se enmarca en el ámbito de la historia de la traducción. Concebida por Bastin como ciencia auxiliar de la historia, la historia 
de la traducción establece una estrecha relación con aquella, de tal manera que una se sirve de la otra: "Comment l'histoire a-t-elle été servie par la traduction et comment s'en est-elle servie ?»(Bastin, 2004: 459). Para la historia de la traducción, la decisión de los traductores a la hora de elegir una u otra obra no es fruto de la casualidad ni se trata de una decisión individual, sino que es producto de una reacción, generalmente colectiva, ante un creciente interés por unos determinados conocimientos (Lépinette, 2016). Así pues, partiremos de las tres preguntas fundamentales con las que, según Berman (1984: 71), debe contar toda teoría histórica de la traducción: pourquoi traduire ?, comment traduire ?, que traduire ? Este es el planteamiento que ha guiado nuestro estudio muy en la línea de la división de Pym (1998) en tres áreas correspondientes a la traducción: la «arqueología» que indaga sobre ¿̇quién tradujo?, ¿̇cuándo?, ¿para quién?, la «crítica histórica» y la «explicación» que pretende demostrar por qué se lleva a cabo la traducción de una obra.

La metodología que hemos seguido en este estudio parte de la división que lleva a cabo Lépinette (1997: 4-6) que distingue unos «objetos privilegiados» en la práctica historiográfica: el peritexto constituido por todas las circunstancias que acompañan a la producción del texto traducido, el metatexto constituido por las reflexiones del traductor sobre el proceso de la traducción que lleva a cabo y finalmente el texto fuente y sus traducciones. Estas indicaciones nos han llevado a contextualizar cultural y socialmente (Sabio Pinilla, 2006: 43) la publicación de la traducción al español del Codex, Pharmacopée française de 1837 para comprender los motivos que han llevado al traductor a verter esta obra al español y no otra y de este modo determinar su finalidad con los datos que el traductor nos proporciona.

\section{Las farmacopeas en el siglo XIX. El Codex, Pharmacopée fra- nçaise y su traducción al español}

El Diccionario de la Lengua Española de la Real Academia define el término «farmacopea» como:

1. f. Libro en que se describen las sustancias medicinales que se usan más comúnmente, y el modo de prepararlas y combinarlas. 2. f. Repertorio que publica oficialmente cada Estado como norma legal para la preparación, experimentación, prescripción, etc., de los medicamentos.

El término «farmacopea» tiene su origen en el griego antiguo ${ }^{1}$ farmakon, que significa 'veneno, droga, medicamento, remedio', y poeio cuyo significado es 'hacer, preparar'. Las farmacopeas, también llamadas códex (lo que les confiere un carácter oficial) nacen de la necesidad de establecer un texto que contenga unas normas de referencia que garanticen la seguridad y eficacia de los productos farmacéuticos. En un principio se trató de

${ }^{1}$ Fue empleado por vez primera por el escritor griego Diógenes Laertius. 
obras regionales o locales, por lo que un mismo país pudo contar con diferentes farmacopeas. Así, por ejemplo, en Francia y en numerosos países europeos, como Alemania, Italia, o Suiza, coexistieron las farmacopeas privadas con las oficiales. A partir del siglo XVIII se produjo la unificación de todas estas obras dando lugar al nacimiento de las farmacopeas nacionales.

El Recetario florentino fue la primera farmacopea impresa en el mundo y fue publicada en Florencia en 1498. Sin embargo, se considera que la primera farmacopea oficial fue la Concordia Apothecariorum Barchinonensium, que se editó en Barcelona en 1511 por Carlos Amorós, Gabriel Estanyol y Miguel Sancho, todos miembros del Colegio de Boticarios de Barcelona.

En España, bajo el reinado de Felipe V, se publicó en 1739 la Pharmacopoeia Matritensis, considerada la primera farmacopea española nacional, que además fue escrita en español y contó con la colaboración del Colegio de Boticarios de Madrid. Durante el reinado de Carlos IV y siendo Godoy primer ministro, se publicó la Pharmacopoea Hispana (1794), de carácter oficial, apareciendo en 1803 la tercera edición de la Pharmacopoea Hispana, donde se recoge la creación de las Ordenanzas de Farmacia y se ordena constituir la Real Junta Superior Gubernativa de la Facultad de Farmacia. En 1817 vio la luz la cuarta edición, en la que no se aprecian grandes cambios a excepción de la orden de que todos los farmacéuticos debían tener un ejemplar de la farmacopea oficial. La quinta edición de esta farmacopea se editó en 1865 bajo el nombre de Farmacopea española. Apreciamos, así que entre estas dos últimas ediciones transcurrieron 48 años sin que hubiera una farmacopea oficial, debido al complejo contexto histórico y político que supuso el gobierno de Fernando VII, lo que propició la aparición de otras farmacopeas no oficiales a las que tuvieron que acudir para sus consultas los boticarios.

Con respecto al país galo, en 1818 se publicó el Codex medicamentarius o Pharmacopoea gallica, primera farmacopea oficial francesa escrita en latín. Aunque se llevaron a cabo diferentes traducciones no oficiales al francés para facilitar la comprensión de la obra y evitar de este modo malas interpretaciones y errores, la traducción de Jourdan (doctor de la Facultad de Medicina de París), publicada en 1821, fue considerada una réplica exacta de la original latina. La segunda edición de la Pharmacopoea gallica data de 1837 y por vez primera se publicó en francés oficialmente con el nombre de Codex, Pharmacopée française. En el préface de esta obra se presentan los motivos que han determinado su publicación en francés:

Après y avoir mûrement réfléchi la commission s'est décidée à rédiger en français la nouvelle édition du Codex. Sans doute la langue latine offre l'avantage d'être la langue commune à tous les peuples policés, et de servir de moyen de communication entre les hommes de science de tous les pays. Mais nous nous sommes rappelé que le Codex était particulièrement destiné à la 
France, qu'il devait servir de guide surtout pour la pratique, et que par conséquent la première condition qu'il devait offrir était d'être bien compris, afin de ne laisser aucun doute dans l'esprit de ceux qui devaient le consulter. D'ailleurs en le rédigeant en latin, la commission n'avait nul moyen d'empêcher qu'une traduction française peut être fidèle, n'en fût immédiatement publiée et sans sa participation. Sous tous ces rapports, la rédaction en français nous a semblé devoir être préférée ( $\mathrm{Co}-$ dex, Pharmacopée française, 1837: XIV).

Así pues, con la intención de poner esta obra al alcance de todos los franceses a quienes iba dirigida, se redacta en francés, aunque (según figura en el préface) los autores mantuvieron la denominación latina junto a la denominación francesa de los medicamentos con la intención de que pudieran ser consultadas todas las preparaciones que en ella figuran por cualquier persona sin importar su procedencia. En la primera página del volumen aparece el escudo de la Facultad de Medicina y la firma del decano, Mateo Orfila, así como el listado de miembros de la comisión designada por el Gobierno para redactar la obra ${ }^{2}$. Estos fueron nombrados por el ministro de la Instrucción Pública y se trataba de profesores de la Facultad de Medicina y de la Escuela Especial de Farmacia de París.

La tercera edición del Codex, Pharmacopée française fue traducida al español por Manuel Jiménez Murillo en 1840 por primera vez y posteriormente esta traducción fue reeditada en 1847. Manuel Jiménez fue profesor de la Facultad de Farmacia de Madrid, donde ocupó la cátedra de Química Médica que con la modificación del plan de estudios de 1845 se convertiría en la cátedra de Química Inorgánica, puesto que ejerció desde 1845 hasta su fallecimiento el 1 de junio de 1859. Asimismo, y según figura en la portada de la obra (en la edición de 1847), fue «vocal de la Junta Suprema de Sanidad del Reino e individuo de la Academia Médica y de la de Ciencias Naturales y del Colegio de Farmacéuticos de esta Corte». Por todo ello, podríamos considerar a Manuel Jiménez como un «traductor de autoridad» (Peña, 1997: 36), es decir, que gozó de gran prestigio en el ámbito académico y se ajustaba al prototipo de traductor decimonónico: era una persona instruida, experto en la materia y con conocimientos de francés que pretendía hacer, de manera altruista, una aportación a la ciencia nacional mediante la traducción de obras científicas actuales y relevantes importadas de Francia. En cuanto a su producción científica, Manuel Jiménez Murillo publicó la Nomenclatura farmacéutica, y sinonimia general de farmacia y de materia médica en 1826, la Tarifa general farmacéutica, ó método general, fácil y sencillo de tasar recetas en 1838, el Tratado de materia farmacéutica en 1838 y el Tratado de farmacia experimental en 1840. En lo concerniente a

${ }^{2}$ Andral, Duméril y Richard (profesores de la Facultad de Medicina de París), Bussy, Caventou, Robiquet, Pelletier y Souberain (profesores de la Escuela de Farmacia). 
su labor traductora, realizó la traducción de Farmacopea razonada, ó tratado de farmacia práctico y teórico de Henry y Guibourt que se publicó en 1830 y el Código de medicamentos, ó Farmacopea francesa publicado como ya hemos señalado en 1840. Estas dos traducciones evidencian el indudable interés que este tipo de obras despertó en el traductor, que, en el prólogo a la tercera edición de la Farmacopea razonada, ó tratado de farmacia práctico y teórico publicada en 1842, se refiere precisamente a la gran aceptación que tuvo en España su traducción, cuya primera edición se agotó rápidamente y dio lugar a una segunda edición e incluso a una tercera: La rapidez con que se ha despachado la traducción que publiqué en el año 1830 de la primera edición de la Farmacopea razonada, demuestra de un modo evidente la aceptación con que ha sido recibida por los profesores de la ciencia de curar, y en especial por los farmacéuticos; y los nuevos pedidos que continuamente se hacen para dentro y fuera del reino, a pesar de haberse concluido los ejemplares de aquella edición hace más de un año, probarían la necesidad de reimprimirla, aun cuando las dos ediciones publicadas posteriormente en Francia no hubiesen hecho hasta cierto punto precisa esta reimpresión para dar a conocer las importantes adiciones y correcciones que contienen, particularmente la tercera y última publicada hace pocos meses (Jiménez, 1842: I).

\section{Las instancias prefaciales o paratexto del traductor}

Consideramos de gran interés detenernos en la figura del traductor decimonónico como intermediario cultural cuyo papel no se reduce tan solo a la traducción de un texto, sino que además se ve en la obligación de intervenir en este como ya hemos señalado más arriba. La inclusión en la obra traducida de prólogos, notas, anexos, etc. (Pinilla y Lépinette, 2009) 3 responde al deseo del traductor de comunicarse con el receptor tendiendo un puente que adquiere especial relevancia al poner en contacto a personas que pertenecen a distintos ámbitos culturales y que no poseen los mismos conocimientos enciclopédicos o las mismas referencias científicas. En el caso que nos ocupa, se trataba de conectar la cultura francesa y la cultura española cuyas diferencias eran notables en el contexto del siglo XIX. Y ahí precisamente es donde el traductor entra en juego, viéndose obligado a tomar la decisión de mantenerse fiel al texto original o bien adaptarlo y acercarlo al receptor meta.

3 Si bien Pinilla y Lépinette (2009) hacen referencia concretamente al traductor del siglo XVIII y se centran en el estudio del paratexto en la obra Physique des arbres (1758) de H. L. Duhamel du Monceau, la reflexión que las autoras hacen sobre el traductor del siglo XVIII es igualmente válida para el estudio de los traductores decimonónicos. 
Centraremos nuestro estudio en los elementos paratextuales que tiene a su alcance el traductor para dirigirse al lector y conversar con él sin la intervención ni del autor ni del editor. Gallego Roca (1994: 165) considera los prólogos, los epílogos y las notas como textos de apoyo o paratextos que aportan toda la información que se requiera sobre el traductor, la génesis de la obra, así como sobre la tradición o cultura en la que el texto se inserta.

El paratexto, considerado como «todo lo que rodea al texto, lo prolonga y completa» (Yuste Frías, 2008: 143), puede provenir tanto del autor y del editor como del traductor. El estudio diacrónico del paratexto adquiere un interés especial para algunos autores, como Bastin (2010: 2), para quien «l'étude du paratexte constitue une tâche primordiale pour l'historien de la traduction et les spécialistes de la genèse des textes et des traductions». Genette (2002: 150) define el prefacio como «toute espèce de texte liminaire (préliminaire ou postliminaire), auctorial ou allographe, consistant en un discours produit à propos du texte qui suit ou qui precède». Para Genette (2002: 151), el prefacio puede recibir diferentes nombres: introduction, avant-propos, prologue, note, notice, avertissement, prélude, discours préliminaire, exorde, avant-dire, proème. El contenido de las instancias prefaciales puede responder a tres funciones: la función informativa, la función de recomendación y el comentario crítico. En el prólogo del Código de medicamentos o Farmacopea francesa 4 , la función informativa se convierte en una explicación práctica de la traducción, ya que es el propio traductor quien se permite reflexionar sobre la traducción que ha llevado a cabo de la obra. La relevancia de estos comentarios radica en hacer visible al traductor en un sentido amplio, ya que desde el momento en que este se dirige al lector a través de un prólogo, de un prefacio, de un epílogo o de una nota, deja de ser un mero transmisor para convertirse en un experto que guía al lector a través del texto traducido.

Es interesante analizar el paratexto para conocer más y mejor al traductor, los motivos que le han llevado a traducir el texto, los métodos de traducción, las dificultades a las que se ha enfrentado, etc. «El prólogo introducción, prefacio, preámbulo, proemio- es el elemento paratextual más representativo y el más estudiado pese a la falta de investigaciones rigurosamente dedicadas al paratexto dentro de los estudios descriptivos de traducción» (Enríquez Aranda, 2003: 331).

Las instancias prefaciales revisten formas muy variadas, pero siempre subyace un único punto en común: «alguien se dirige a otra persona». Detrás de todos estos textos siempre hay un «yo» que tiene interés en dirigirse a un «tú» por un motivo determinado. Este «tú » puede ser evocado directamente o de manera implícita. Muy variadas pueden ser las razones por las que un traductor decide tomar la palabra a través del prólogo o prefacio. Para Genette, si el traductor comenta su propia traducción deja de ser

4 En la edición de 1847 el título aparece como: Codex o Farmacopea francesa. 
alógrafo, ya que es autor de su traducción, es decir, se distancia para colocarse justo enfrente, toma perspectiva y se convierte temporalmente en otra persona, podríamos decir que en este caso «le traducteur est un autre»5.

El prólogo es un género que se adapta a los intereses del autor o, en este caso, del traductor. La labor del traductor no queda reducida a la mera traducción, sino que va más allá permitiéndose informar al lector de las motivaciones que le han llevado a tomar la decisión de emprender la traducción de la obra:

Si l'on considère l'histoire de la traduction et de la traductologie, on constate [...] que ce sont les traducteurs eux-mêmes qui éprouvent le besoin, de façon compulsive, de parler de leur travail [...] les traducteurs n'ont cessé de prendre leur travail pour objet de discours, c'est-à-dire de pratiquer des formes de traductologie (Ballard, 2007: 273).

El prólogo tiene asimismo un carácter publicitario ante la imposibilidad del texto para presentarse a sí mismo. Es el propio autor o, en nuestro caso, el traductor, quien, a través del prólogo o del prefacio, presenta el texto al lector e intenta captar su atención y despertar su interés. De este modo, se establece una estrecha relación entre autor, texto, lector, editor y traductor.

En los textos traducidos podemos observar la presencia de tres clases de paratextualidad: el paratexto del autor o peritexto, el paratexto del editor o epitexto, a lo que se debe añadir el paratexto del traductor que se suele presentar en forma de prefacio o prólogo. Para Risterucci-Roudnicky (2008: 48), los prefacios o prólogos del traductor tienen una clara función mediadora lingüística e intercultural entre la obra traducida y el lector, ya que preparan a este para la recepción de un universo muy alejado del suyo. Del mismo modo, Peña (1997: 39) considera que cuando los prólogos establecen un diálogo entre la cultura origen y la cultura de llegada, se produce una intermediación cultural que pretende acercar una cultura foránea a un lector que la siente como extraña, diferente a la suya.

\section{El prólogo del Código de medicamentos o Farmacopea fran- cesa}

Manuel Jiménez, como ya se ha indicado más arriba, traduce al español la Pharmacopée française y se sirve del prólogo de su traducción para explicar los motivos que le han llevado a traducir esta obra. El traductor se dirige directamente al lector con la intención de informarle acerca del proceso traductor y de la finalidad de la traducción (en el caso del prólogo), así como para completar la información del texto origen francés mediante la adaptación a la cultura española de las diferentes recetas de medicamentos

5 Parafraseamos la conocida frase que Rimbaud escribió en una carta a Paul Demeny en 1871: «Je est un autre». 
(en el caso de las notas del traductor). Para ello el traductor vierte en el prólogo y en las notas una serie de comentarios a través de los cuales teoriza en cierto modo sobre la traducción en general y sobre la utilidad de la obra traducida en particular: "La préface est l'occasion pour le traducteur de parler de sa pratique, que ce soit sous la forme de réfléxions générales ou d'analyses détaillées» (Hersant, 2018). El discurso teórico decimonónico sobre la traducción aparece diseminado en prólogos y tratados en los que el traductor reflexiona no solo sobre la traducción y el proceso traductor, sino que además teoriza sobre diferentes temas, como la historia, la lingüística, la crítica literaria. De este modo el traductor pasa de ser un mero transmisor o comunicador intercultural para convertirse en el experto en el que el lector puede confiar para que le facilite la travesía. Así pues, el lector avanza por el texto de la mano del traductor que le proporciona las herramientas adecuadas (a través de los comentarios e indicaciones del prólogo y de las notas a pie) para que no lo perciba como un texto ajeno por haber sido redactado en otro idioma y pertenecer a otra cultura y así pueda serle útil lo que en definitiva constituye la finalidad última de la traducción de esta obra.

El prólogo de una traducción es, sobre todo, un instrumento de adaptación (Genette, 2002: 411) que permite al traductor dar a conocer al lector todas aquellas modificaciones que ha realizado con respecto al texto original, bien porque se ha visto obligado a llevarlas a cabo o bien porque él las ha considerado pertinentes. En el caso de la traducción de la Pharmacopée française, como ocurría en la mayor parte de las traducciones de obras científicas y técnicas del siglo XIX, el traductor añadió una serie de notas (como él mismo afirma en la portada): «Notas, propiedades, usos y dosis de los medicamentos que contiene y un suplemento con 152 fórmulas». Estas últimas se ven ampliadas a 179 en la segunda edición donde explica que se trata de «179 nuevas fórmulas de la hispana y de diferentes obras». Así pues, el traductor «se apropia» de la obra, la hace suya a través de la traducción y añade todos aquellos elementos que, según su opinión, completan la traducción al español de la obra original francesa respondiendo a los intereses del lector:

Por via ${ }^{6}$ de suplemento y con el objeto de hacer mas interesante el uso de esta Farmacopea en España, hemos añadido las fórmulas mas usuales de la nuestra con el fin de que los profesores tengan en un volumen la Farmacopea francesa y lo mas principal de la española, y ademas las fórmulas que suelen usarse y no se encuentran en ninguna de las dos y si en otras farmacopeas, formularios y tratados de terapéutica, todo con el objeto de que pueda ser útil á las tres clases de profesores de la ciencia de curar, á lo que contribuirá tambien el haber

${ }^{6}$ En todas las citas de la Farmacopea francesa hemos mantenido la grafía original por lo que en numerosas ocasiones se puede echar de menos alguna tilde o bien puede resultar extraña la grafía de algunas palabras. 
puesto al final de cada fórmula sus propiedades médicas y las dosis en que puede administrarse (Jiménez, 1840: IV).

Por otra parte, también el traductor lleva a cabo algunas supresiones de elementos que, siendo específicos y de uso común en Francia, no son utilizados en España. Todo esto queda aclarado en el prólogo:

En su traducción hemos hecho algunas alteraciones indispensables dirigidas todas a acomodarla a nuestros usos y necesidades y a ponerla al alcance de los que la han de consultar. Por esta razón hemos suprimido tanto en la tabla de medicamentos simples que va al principio de la obra, como en el índice general que está al fin de ella, el asterisco con que en el original están marcadas las sustancias o medicamentos que en Francia son de absoluta necesidad en las oficinas en razón de su uso frecuente, pero entre las que se encuentran muchas que aquí no tienen uso alguno, al paso que otras, que entre nosotros son indispensables, no están indicadas como tales para aquel país (Jiménez, 1840: II).

Manuel Jiménez se permite incluso corregir los errores que (según él) detecta en el original y así lo especifica en el prólogo:

También hemos reformado algunos nombres unas veces para poner en su lugar el perteneciente a la planta o parte de ella que usamos nosotros, y otras por no ser el que verdaderamente debiera (Jiménez, 1840: II).

El prólogo se presenta como espacio metadiscursivo o, en el caso que nos ocupa, metatraductivo (Hersant, 2018) ya que el traductor reflexiona sobre el proceso de la traducción y sobre el resultado final haciendo partícipe al lector de este proceso. Auténtico tesoro de información traductológica (Peña, 1997: 45), el prólogo es un importante instrumento de mediación interlingüística e intercultural al conectar dos culturas diferentes, dos destinatarios pertenecientes a universos alejados: «Les préfaces ont une importante fonction de médiation linguistique et interculturelle entre l'œuvre et le lecteur, car elles visent à préparer le destinataire étranger à un univers éloigné du sien» (Eco, 1998: 19).

La estructura del prólogo que precede a la traducción al español de Manuel Jiménez de la Pharmacopée française está organizada en cinco apartados:

1. El traductor contextualiza la obra original francesa, situándola en una época en la que los avances de la Química y, por consiguiente, de la Farmacia hacen imprescindible la publicación actualizada de una obra que recoge todas las fórmulas de los nuevos medicamentos que ya se estaban empleando en otros países europeos, como Francia, y, además, permite hacer llegar a la población el nombre de las nuevas sustancias: 
Los numerosos descubrimientos con que la química y farmacia han enriquecido en estos últimos tiempos la terapéutica y materia farmacéutica han producido en el sistema médico notables e interesantísimas variaciones que, introducidas oportunamente por los prácticos en la curación de todo género de dolencias, han sido coronadas con el más feliz resultado. Mas en vano aspirarán los profesores de la ciencia de curar a repetir y perfeccionar sus observaciones, sacando de ellas el fruto que la humanidad doliente reclama, mientras carecemos de códigos o farmacopeas en que se hallen consignadas las fórmulas de los nuevos medicamentos poco generalizados hasta el día en España (Jiménez, 1840: I).

2. El traductor expone los motivos que le han llevado a emprender la traducción de esta obra. Se convierte en abanderado de la causa denunciando a través del prólogo el hecho de que aún no se haya publicado una versión actualizada de la Pharmacopoea Hispana, a pesar de que esta ya estaba concluida:

De esperar era que por la autoridad competente se diesen las oportunas providencias a fin de llenar este vacío $\mathrm{y}$ de poner a los profesores españoles al nivel de los extranjeros; pero por desgracia se ha mirado este asunto con tanto abandono, que a pesar de haberse concluido hace tiempo la última edición de la Farmacopea española, insuficiente además en el estado actual de la ciencia, no hemos visto realizada su proyectada nueva edición, que debía haber satisfecho cumplidamente los deseos y necesidades de nuestros dignos comprofesores (Jiménez, 1840: I).

3. Se hace referencia a los especialistas que han colaborado en la redacción de la obra:

Esta consideración nos ha movido principalmente a dar a luz la traducción del nuevo Código de medicamentos o Farmacopea francesa publicada en 1837, y redactada por una comisión especial nombrada a tal efecto, compuesta de individuos cuyos nombres solos son la suficiente garantia de la escrupulosidad, inteligencia y acierto que ha presidido á su redaccion. Entre ellos figuran los mas distinguidos médicos y farmacéuticos, á cuyo celo y constante laboriosidad son deudoras en gran parte la química y farmacia de la brillante posicion que ocupan en el dia al lado de las demas ciencias (Jiménez, 1840: I).

4. El traductor presenta y elogia el texto original:

El nuevo Código enteramente diverso del antiguo ya por su método, ya por las manipulaciones nuevamente 
adoptadas para la elaboración de muchos medicamentos y ya también por el gran número de sustancias nuevas que incluye, puede mirarse como la compilación de las fórmulas mas escojidas de los medicamentos de uso frecuente en la actualidad, y a cuya elaboración puede entregarse el farmacéutico con la confianza de que sus fórmulas han sido ensayadas y comprobadas por la experiencia. Esta cualidad relevante sobre otras Farmacopeas es un nuevo motivo que nos ha inducido a presentar al público esta obra, única en su género, y tan provechosa para los profesores como necesaria para los alumnos de los tres ramos de la ciencia de curar (Jiménez, 1840: II).

5. El traductor analiza su propia traducción dando cuenta al lector de todos los cambios y adaptaciones que ha llevado a cabo con respecto al texto original:

En su traducción hemos hecho algunas alteraciones indispensables dirigidas todas a acomodarla a nuestros usos y necesidades y a ponerla al alcance de los que la han de consultar. Por esta razón hemos suprimido tanto en la tabla de medicamentos simples que va al principio de la obra como en el índice general que está al fin de ella, el asterisco con que en el original están marcadas las sustancias o medicamentos que en Francia son de absoluta necesidad en las oficinas en razón de su uso frecuente, pero entre las que se encuentran muchas que aquí no tienen uso alguno, al paso que otras, que entre nosotros son indispensables, no están indicadas como tales para aquel país [...]. También hemos reformado algunos nombres unas veces para poner en su lugar el perteneciente a la planta o parte de ella que usamos nosotros, y otras por no ser el que verdaderamente debiera (Jiménez, 1840: II).

Entre las modificaciones y adaptaciones culturales que lleva a cabo Manuel Jiménez en su traducción, y según él mismo indica en el prólogo, se encuentran las referencias a pesos y medidas contenidos en las diferentes recetas y elaboraciones presentes en la obra:

Las cantidades de los medicamentos que entran en la composición de las fórmulas, y que en el original se hallan expresadas en números o partes, las hemos simplificado siempre que nos ha sido posible hacerlo sin variar su proporción, y respecto a las que están indicadas en pesos franceses tanto antiguos como modernos, las hemos reducido a la libra castellana de 16 onzas y sus divisiones (Jiménez, 1840: II). 
En otras ocasiones, en la concentración de alcohol de algunas preparaciones, el traductor ha suprimido la equivalencia entre el aerómetro de Cartier y alcoholímetro de Gay-Lussac, ya que, según palabras del propio Manuel Jiménez, este último está en desuso en España, por lo que no tiene sentido alguno que aparezca en la traducción española, aunque el traductor mantiene en su versión la tabla de equivalencias procedente de la obra original:

Refiriéndome al areómetro de Cartier para indicar la
concentración del alcool, que se emplea en la prepara-
ción de diversos medicamentos, hemos omitido sus co-
rrespondencias con el alcoómetro centesimal de Gay-
Lussac en razón a no hallarse en uso en España: esto no
obstante hemos conservado en los preliminares la tabla
que trae el original sobre la relacion de los grados de am-
bos areómetros para satisfacer la curiosidad del que
desee saber sus equivalentes; debiendo tenerse presente
para su inteligencia, que estando dividido el alcoómetro
centesimal en cien grados desiguales en longitud, de los
que el punto cero corresponde al agua pura y el grado
10o al alcool anhidro, cada grado intermedio indica en
centésimas partes la cantidad de alcool anhidro conte-
nido en un alcool dado; de modo que, por ejemplo, el
grado 88 centésimal, que en la tabla corresponde al $35^{\circ}$
de Cartier, nos dice que el alcool de esta graduacion con-
tiene 88 por 100 de alcool anhidro, entendiéndose en el
supuesto de que la temperatura ha de ser de $15 .^{\circ}$ (Jimé-
nez, 1840 : III).

Una de las dificultades con las que se enfrentaron los traductores del siglo XIX fue la reforma de la terminología química que supuso la introducción de muchos de los nombres que se emplean en la actualidad, como oxígeno, hidrógeno, óxido carbónico, sulfato de sodio, y el abandono progresivo del acervo terminológico procedente de la alquimia, la minería o la farmacia vigente hasta el momento (Álvarez Jurado, 2016: 291). Se produjo un profundo debate a finales del siglo XVIII y principios del XIX en relación con las nuevas denominaciones de los elementos químicos. El ámbito de la Farmacia y de la Química es, sin duda, uno de los dominios más interesantes por la gran cantidad de problemas de traducción que generó el trasvase de la terminología médico-farmacéutica en general (Luque Janodet, 2020: 450). El interés ilustrado por construir un lenguaje racional y sistemático para las ciencias (Bertomeu y Muñoz, 2010: 214) dio lugar a un cambio importante en el nombre con el que se denominó a los elementos. Estos, que hasta el momento habían sido nombrados por sus características físicas, los modos de preparación o las propiedades terapéuticas, pasan a ser denominados por su composición. Así pues y como hemos señalado más arriba, la adaptación de la terminología química a las diferentes lenguas provocó un profundo debate que dividió la opinión de los especialistas, entre los que se 
inclinaban por la unificación del lenguaje científico manteniendo el término francés sin modificaciones y los que preferían la adaptación al español, aunque los términos resultantes de esta adaptación difirieran mucho de los términos originales franceses.

Manuel Jiménez confiesa no haberse alejado de la nomenclatura de la Pharmacopée française salvo en la omisión del término en latín:

En nada hemos variado la nomenclatura del original; unicamente hemos suprimido el nombre latino, que va á la cabeza de cada fórmula y al frente de las sustancias que la componen, por parecernos una redundancia superflua, puesto que estando colocadas al principio de la obra por orden alfabético todas las drogas simples que entran en las fórmulas de la Farmacopea, puede con facilidad resolverse cualquiera duda que sobre su naturaleza pudiese ocurrir, como igualmente respecto de los compuestos cuyos equivalentes pueden buscarse á la cabeza de sus respectivas fórmulas (Jiménez, 1840: III).

\section{Las notas del traductor del Código de medicamentos o Farma- copea francesa}

Al igual que los prólogos, las notas del traductor han suscitado con frecuencia el interés de los investigadores, quienes se han planteado su eficacia dentro del texto, así como su utilidad para el lector. El traductor, como mediador entre textos y entre culturas, interpreta y traslada el contenido de un texto a otra lengua y este trasvase se produce normalmente de manera imperceptible para el lector, lo que hace en cierto modo invisible al traductor. Sin embargo, llegado el momento, el traductor toma la palabra y sale de esa invisibilidad, de ese anonimato (Arbulu, 2020: 543) a través de las notas a pie con la intención de aportar información puntual, una explicación relacionada con algún aspecto concreto del texto origen. De este modo, la función principal de las notas del traductor consiste en restituir la obra original en un contexto lingüístico, cultural, geográfico y temporal diferente. El traductor adquiere protagonismo y se responsabiliza de las posibles lagunas que el texto que ha traducido haya podido generar. Con la intención de arrojar una luz y aclarar estas dudas, se dirige al lector y entabla con él una comunicación en la que le transmite las claves para una correcta comprensión de su traducción: «Su voluntad suele ser la de completar, enriquecer, aclarar el contenido del original» (Arbulu, 2020: 545). En la Farmacopea francesa hemos encontrado 84 notas del traductor $(\mathrm{N} \mathrm{d} \mathrm{T})$ en las que se comparan las recetas del texto original francés con las de la traducción, proporcionando de este modo al lector español la información que necesita para poder interpretar y elaborar las recetas francesas:

a) La tintura que con este nombre trae la hispana se llama vinosa, y se prepara con 8 onzas de limaduras de hierro, 16 de tártaro y 16 libras de agua, se cuece todo en una vasija de hierro por 12 horas agitándolo continuamente 
y añadiendo la cantidad de agua hirviendo necesaria; se decanta entonces el líquido, se filtra, y se evapora en una vasija vidriada hasta la consistencia de estracto blando; se ponen en digestion por 8 dias tres onzas de la masa que resulta con 1 a de vino blanco y media de alcool, y se filtra (Código de medicamentos o Farmacopea francesa, 1840: 105).

b) Este aceite se prepara segun la hispana cociendo los huevos en agua hasta que esten duros; se sacan las yemas, se desmenuzan con un rallo, y se ponen en una vasija de hierro á fuego lento, agitándolas continuamente con una espátula hasta que adquieran color rojizo y suden aceite: entonces se ponen al instante en un saco de lienzo, y se esprimen en una prensa caliente (Código de medicamentos o Farmacopea francesa, 1840: 168, NdT).

c) La hispana trae un cocimiento de polígala, que se prepara cociendo una onza de la planta en la suficiente cantidad de agua para obtener 24 onzas de producto (Código de medicamentos o Farmacopea francesa, 1840: $169, \mathrm{NdT}$ ).

d) La farmacopea hispana dice se corte ó coagule la leche, mezclándola con un poco de flor de cardo ó de cualquiera ácido vegetal, y que colado se clarifique añadiendo á cada libra de suero medie escrúpulo de cremor tártaro ademas de la clara de huevo, y echándole cuando está hirviendo un poco de suero frio (Código de medicamentos o Farmacopea francesa, 1840: 174, NdT).

e) En nuestra farmacopea se hallan tres fórmulas de cocimientos blancos que difieren de este, y son el blanco gomoso, el blanco tenue, y el blanco de Sydenham. Este se prepara cociendo ligeramente media, onza de cuerno de ciervo y dos de pan en 6 libras de agua, colándolo y dulcificándolo con 4 onzas de jarabe simple, y aromatizándole si se quiere con 2 dracmas de agua de azahar ó de canela lacticinosa.

El blanco gomoso se prepara con 2 dracmas de cuerno de ciervo levigado, media onza de goma arábiga y otra media de azucar blanca, que se cuecen en libra y media de agua hasta que quede en una, y se cuela por una cedacilla.

El blanco tenue se hace cociendo ligeramente media onza de cuerno de ciervo levigado, 1 de goma y a de azúcar en 4 libras de agua, y colando el líquido (Código de medicamentos o Farmacopea francesa, 1840: 175, NdT).

f) El cocimiento de leños que trae la hispana tiene bastante analogía con esta apocema, pues se prepara poniendo a 
onzas de raspaduras de palo santo y otras a de zarza parrilla cortada en pedacitos con 8 libras de agua en una vasija tapada por 12 horas; se cuece á fuego lento hasta reducir el líquido á 4 libras, se añade al fin una onza de sasafrás rasurado y una dracma de regaliz raspado y contundido, se cuela, se deja aposar, y se decanta (Código de medicamentos o Farmacopea francesa, 1840: $176, \mathrm{NdT})$.

g) La llamada en la farmacopea hispana mistura antiemética se prepara con 1 onza de agua comun, 1 dracma de la lacticinosa de canela, media dracma de sal de ajenjos, y 6 dracmas de zumo de limon, cuyas sustancias se mezclan para que lo tome el enfermo de una vez (Código de medicamentos o Farmacopea francesa, 1840: 184, $\mathrm{NdT}$ ).

h) El bálsamo católico de la hispana se diferencia del de esta fórmula en que en lugar de angélica entra acoro, no lleva acíbar ni incienso, y sí 2 onzas de estoraque y otras 2 de cada uno de los bálsamos en lugar de tres, y la mitad del hipericón (Código de medicamentos o Farmacopea francesa, 1840: 197, NdT).

i) La farmacopea hispana trae diferente método para obtener esta agua, la de rosas, sauco y semejantes, el cual se reduce a dejar las flores en maceración con el agua por 2 días, destilarlas hasta sacar la mitad, y añadir un poco de alcohol (Código de medicamentos o Farmacopea francesa, 1840: 219, NdT).

Asimismo, podemos observar cómo el traductor sustituye en su traducción algunos elementos de las recetas francesas por equivalentes de la cultura española:

ARSENIATE DE SOUDE

Nitrate de soude $\quad 100$

Acide arsénieux $\quad 116$

Mélangez exactement les deux substances ; chauffez au

rouge dans un creuset de Hesse

(Codex, Pharmacopée française, 1837: 115).

$\begin{array}{lc}\text { ARSENIATO DE SOSA (p.80) } \\ \text { Nitrato de Sosa } & 100 \\ \text { Acido Arsenioso } & 116\end{array}$

Se mezclan exactamente estas dos sustancias y se esponen a un calor rojo en un crisol de Zamora.

(Código de medicamentos o Farmacopea francesa, 1840: 80).

El creuset de Hesse es reemplazado en la traducción española por «crisol de Zamora». Ambos son recipientes refractarios resistentes a las altas temperaturas. Mientras que el creuset es de origen alemán, el «crisol» 
tiene un origen español. Este es un claro ejemplo de la mediación cultural ejercida por el traductor adaptando los elementos culturales del texto original francés a la cultura española.

\section{Conclusión}

Partiendo de los presupuestos teóricos que fundamentan la investigación en torno al paratexto, hemos propuesto un estudio del prólogo y las notas del traductor en las traducciones decimonónicas de obras científicas. Para ello hemos utilizado como corpus el prólogo y las notas que contiene la traducción al español del Codex, Pharmacopée française de 1837. Hemos de aclarar que las conclusiones que se derivan de esta investigación están restringidas al corpus estudiado, por lo que proponemos como líneas futuras la continuación de este estudio con una ampliación del corpus a otras traducciones decimonónicas de obras científicas paralelas del ámbito farmacéutico o de otros ámbitos científicos, lo que nos servirá para poder determinar si realmente el comportamiento de Manuel Jiménez como traductor de la Pharmacopée française al español era lo habitual en el siglo XIX o si, por el contrario, se trató de una práctica aislada y no extendida a otros traductores y a otras traducciones.

Como señalábamos al comienzo de este estudio, partiendo del concepto de la traducción como reescritura, concluimos que el texto que hemos analizado puede ser considerado como una reescritura a cargo de Manuel Jiménez, quien añadió, eliminó y por consiguiente adaptó el texto de la Pharmacopée française a su propia cultura, es decir, a la cultura española con la finalidad de que el lector hispano lo adoptara como propio a falta de una actualización de la Pharmacopoea Hispana. El traductor Manuel Jiménez guía al lector en su recorrido textual haciendo posible el diálogo entre los dos textos (TO y TM) situándolos frente a frente. El traductor se apropia del texto original y lo trasvasa al texto meta no sin antes operar en él una serie de modificaciones, adiciones y eliminaciones con la finalidad de que el texto traducido resulte más natural, más cercano al receptor que en este tipo de obras tiene un perfil muy específico, ya que suelen ir destinadas a farmacéuticos, médicos y en general personas de formación especializada en este ámbito:

Nuestro objeto ha sido evitar á los farmacéuticos el trabajo de hacer pruebas y ensayos generalmente perjudiciales á sus intereses, y sobre, todo desvanecer la incertidumbre que podrian tener los médicos acerca del procedimiento empleado en la preparación de un medicamento, y por consiguiente de la dosis en que deberian administrarle (Jiménez, 1840: VII)

Todas estas modificaciones del texto francés son comunicadas al receptor a través del prólogo del traductor, así como de las notas a pie que se convierten en el espacio reservado por el traductor para comunicarse con el 
receptor y hacerle partícipe del proceso traductor. Esto demuestra la relevancia que adquieren las instancias paratextuales del texto traducido (tanto prólogos como notas del traductor), por lo que hemos de admitir con Dokhtourichvili (2017: 175) que las notas a pie no son «la honte du traducteur», como afirma Aury (1964: 11), sino que constituyen un valioso instrumento imprescindible para el traductor.

\section{REFERENCIAS BIBLIOGRÁFICAS}

ÁlVAREZ JURADO, Manuela (2016): «Un acercamiento a la preocupación decimonónica por los fraudes alimentarios: la traducción y recepción en España del Dictionnaire des altérations et falsifications des substances alimentaires de Alphonse Chevallier». Onomázein, 33, 289-309. DOI: 10.7764/onomazein.33.17.

ARBULU BARTUREN, María Begoña (2020): «La visibilidad del traductor: las notas al pie de página en las traducciones españolas de la Grammatica della fantasia de Gianni Rodari». Orillas, 9, 543-571.

AURY, Dominique (1963): Introduction à Georges Mounin. Les problèmes théoriques de la traduction. París, Gallimard.

BALLARD, Michel (1995): De Cicéron à Benjamin. Traducteurs, traductions, réflexions. Lille, Presses Universitaires de Lille.

BASTIN, Georges L. [dir.] (2004): «Introduction». Meta 49: 3 (Histoire de la traduction et traduction de l'histoire / History of translation and translation of history). URL : https://www.erudit.org/fr/revues/meta/2004-v49-n3meta816.

BASTIN, Georges L. (2010): "Traduction et histoire. Les indispensables paratextes», in Juan Carlos de Miguel et al. (eds.), Hommage à Brigitte Lépinette. Valencia, Universitat de València, 47-59.

BERMAN, Antoine (1984): L'épreuve de l'étranger. Culture et traduction dans l'Allemagne romantique. París, Gallimard.

BERMAN, Antoine (1989): «La traduction et ses discours». Meta, 34: 4, 672-679. DOI : https://doi.org/10.7202/002062ar.

BERMAN, Antoine (2001): «Au début était le traducteur». TTR: Traduction, Terminologie, Rédaction, 14: 2, 15-18. DOI: https://doi.org/10.7202/000566ar.

BERTOMEU SÁNCHEZ, José Ramón \& Rosa MuÑOZ BELlo (2010): «Resistencias, novedades y negociaciones: la terminología química durante la primera mitad del siglo XIX en España». Dynamis, 30, 213-238. URL: https://scielo.isciii.es/scielo.php?script=sci_arttext\&pid=So211-95362010000100009.

Codex, Pharmacopée française. Rédigée par ordre du Gouvernement par une commission composée de MM. les professeurs de la Faculté de Médecine et de l’École Spéciale de Pharmacie de Paris. París, Bechet Jeune Libraire-Editeur, 1837 . 
Código de medicamentos o Farmacopea francesa.Traducida al castellano y adaptada por D. Manuel Jiménez Murillo. Madrid, Imprenta de D. N. Sanchiz,1840.

DOKHTOURICHVILI, Mzago (2017): "La traduction comme source de création. Le paratexte de traducteur». Études Interdisciplinaires en Sciences humaines, 4, 170-187. URL: https://ojs.iliauni.edu.ge/index.php/eish/article/view/361.

EcO, Umberto (1998): «Introduction à Exercices de style de Raymond Queneau». Formules, 2, 15-29.

ENRÍQUEZ ARANDA, Mercedes (2002): «El paratexto en la traducción. Un ejemplo en la poesía de John Keats traducido al español». Interlingüística, 13: 2, 3140.

GALLEGo RocA, Miguel (1994): Traducción y literatura: Los estudios literarios ante las obras traducidas. Madrid, Júcar.

GenetTe, Gérard (1982): Palimpsestes. La littérature au second degré. París, Seuil.

GENETTE, Gérard (2002 [1987]): Seuils, París, Gallimard.

GuZMÁN, María Constanza \& Ana Marcela GuZMÁN (2009): «Hacia una conceptualización del legado del traductor». Forma y Función, 22: 1, 203-224. URL: https://dialnet.unirioja.es/descarga/articulo/6454276.pdf.

HERSANT, Patrick (2018): «Portraits du traducteur en préfacier». Palimpsestes, 31, 17-36. DOI: 10.4000/palimpsestes.2552.

JimÉNEZ MuRILLO, Manuel (1840): «Prólogo», in Código de medicamentos o Farmacopea francesa. Traducida al castellano y adaptada por D. Manuel Jiménez Murillo. Madrid, Imprenta de D. N. Sanchiz, I-IV.

JIMÉNEZ MURILLO, Manuel (1842): «Advertencia sobre esta edición», in Farmacopea razonada o Tratado de Farmacia práctico y teórico. Madrid, Imprenta de D.N. Sanchiz, 3 a ed., I-II.

LEFEVERE, André (1992): Translation, Rewriting and the Manipulation of Literary Fame. Londres \& Nueva York, Routledge.

LÉPINETTE, Brigitte (1997): La historia de la traducción. Metodología. Apuntes bibliográficos. Valencia, LynX (Documentos de trabajo, vol. 14).

LÉPINETTE, Brigitte (2016): «La historiografía traducida del francés (1800-1822)», in Brigitte Lépinette \& Julia Pinilla (eds.), Reconstruyendo el pasado de la traducción. Granada, Comares, 2-49.

LETAWE, Céline (2018): «Quand le traducteur-préfacier parle de traduction. Fonctions d'un discours entre préface allographe et préface auctoriale». Palimpsestes, 31, 37-48. DOI: 10.4000/palimpsestes.2583.

LUQUE JANODET, Francisco (2020): «Un acercamiento a la recepción de la terminología farmacéutica en el siglo XIX: a propósito de la traducción al español del Manuel du pharmacien ou précis élémentaire de pharmacie de Alphonse Chevallier y Pierre Idt». Anales de Filología Francesa, 28, 449-470. DOI: https://doi.org/10.6018/analesff.425741. 
PEÑA, Salvador (1997): «El traductor en su jaula: hacia una pauta de análisis de traducciones», in Esther Morillas \& Juan Pablo Arias (eds.), El papel del traductor. Salamanca, Colegio de España, 19-31.

PINILLA MARTÍNEZ, Julia \& Brigitte LÉPINETTE, (2009): «La aportación propia del traductor al texto científico-técnico traducido o el afán de divulgación de un saber foráneo: a propósito del paratexto en una traducción al español de $\mathrm{H}$. L. Duhamel du Monceau (1700-1782)». Cuadernos del Instituto de Historia de la Lengua, 3, 109-126.

PyM, Anthony (1998): Method in Translation History. Manchester, St. Jérome.

RISTERUCCI-ROUDNICKY, Danielle (2008): Introduction à l'analyse des ouvres traduites. París, Armand Colin.

SABio PINILLA, José Antonio (2006): «La metodología en Historia de la Traducción: estado de la cuestión». Sendebar, 17, 21-47. DOI: https://doi.org/10.30827/sendebar.v17io.1007.

TAHIR-GÜRÇAĞLAR, Şehnaz (2002): «What texts dont't tell. The uses of paratexts in translation research», in Theo Hermans (ed.), Crosscultural Transgressions. Londres \& Nueva York, Routledge, 44-6o.

YUSTE FRÍAS, José (2008): «Pensar en traducir la imagen en publicidad: el sentido de la mirada». Pensar la Publicidad. Revista Internacional de Investigaciones Publicitarias, 2: 1, 141-170. URL: https://revistas.ucm.es/index.php/PEPU/article/view/PEPUo808120141A.

YUSTE FRIAS, José (2010): «Au seuil de la traduction : la paratraduction», in Ton Naaijkens (ed.), Ever or Incident. On the Rôle of Translation in the Dymamics of Cultural Exchange / Événement ou Incident. Du rôle des traductions dans les processus d'échanges culturels. Berna, Peter Lang, 287-316.

YUSTE FRÍAS, José (2011): «Traducir para la pantalla: el traductor entre el texto y la imagen», in Elena di Giovanni (coord.), Diálogos intertextuales 5, between text and receiver: translation and accessibility. Berna, Peter Lang, 57-88. 